\title{
Physiological Effects of the BOKS Before-School Physical Activity Program for Preadolescent Youth
}

\author{
Wayne L. Westcott ${ }^{1 *}$, Kim Puhala ${ }^{2}$, Amanda Colligan ${ }^{3}$, Rita LaRosa Loud ${ }^{4}$ and Robert Cobbett ${ }^{4}$ \\ ${ }^{1}$ Director of Exercise Science, Quincy College, Quincy, MA, USA \\ ${ }^{2}$ Vice-President, Institutional Research and Assessment, Quincy College, MA, USA \\ ${ }^{3}$ Survey Analyst, Institutional Research and Assessment, Quincy College, MA, USA \\ ${ }^{4}$ Exercise Science Faculty, Quincy College, MA, USA
}

Received: March 01, 2015; Accepted: May 20, 2015; Published: June 13, 2015

*Corresponding author: Wayne L. Westcott, Ph.D., Director of Exercise Science, Quincy, College, 1250 Hancock Street, Quincy, MA, USA. Tel: 617-9841716; Fax: 617-984-1678. E-mail: wwestcott@quincycollege.edu

\begin{abstract}
Approximately $30 \%$ of elementary school children are overweight or obese, and approximately $50 \%$ do not meet the minimum recommendations for physical activity. In an attempt to address these issues, an innovative before-school exercise program called BOKS (Build Our Kid's Success) was introduced in Massachusetts, and is presently implemented in more than 1,200 schools throughout the United States and other countries. The BOKS program provides 50 minutes of large muscle physical activity, 3 days a week, performed through a variety of locomotor movements, running games, relays, body weight exercises, and dynamic stretches. The purpose of this study was to assess 81 BOKS physical activity program participants ( 46 males, 35 females; mean age 7.6 years) and 31 control subjects ( 24 males, 7 females; mean age 8.7 years) for changes in height, bodyweight, percent body fat, fat weight, lean weight, muscle strength, joint flexibility, and aerobic performance before and after a 9-week training period. Even when controlling for gender, age, and baseline measurements, the exercise group attained significantly greater improvements $(P<0.05)$ than the control group in percent body fat, fat weight, and aerobic performance. It was concluded that the BOKS before-school exercise program was effective for improving specific health and fitness components in elementary-aged children. Recommendations for improving the exercise program outcomes were presented.
\end{abstract}

Keywords: Youth fitness; Preadolescent exercise; Children's physical activity program

\section{Introduction}

Approximately one in three elementary school students in the United States is overweight or obese [1]. Between 1980 and 2010 , the prevalence of obesity in 6 to 11 year old boys and girls increased almost threefold from $6.5 \%$ to $18.0 \%$ [1]. Within this same time period, children's muscular fitness and fundamental motor skills declined significantly [2,3]. These trends appear to be associated with cardio-metabolic biomarkers in unfit youth, including elevated blood pressure, undesirable blood lipid profiles, insulin resistance, and endothelial function [4], that have been associated with metabolic risk in preadolescents [5]. Other researchers [6] have reported an inverse relationship between physical activity and bodyweight in youth.

As important as physical activity appears to be for body composition, fitness, and health, studies show that only $30 \%$ to $42 \%$ of children ages 6 through 11 attain the recommended 60 minutes of large muscle movement most days of the week [7-9].

Clearly, time spent viewing screens reduces the time available for performing physical activity. On average, young people occupy 4 hours of every day using electronic media [10], and by high-school graduation they are likely to have accumulated more television time than class time [11]. However, elementary schools have typically placed a low emphasis on physical education compared to academic subjects $[12,13]$. Daily physical education is provided in only $4 \%$ of American elementary schools [14], and during any given week only 1 in 2 students attended physical education classes [15]. Children who do participate in physical education may spend only $10 \%$ to $36 \%$ of the class time in moderate-to-vigorous large muscle activity [16,17]. Consequently, most elementary students do not experience much physical activity during the school day.

One approach for providing supervised exercise to preadolescents is the Youth Fit For Life program conducted in YMCA after-school day care centers [12,18]. Studies with more than 1,000 children (ages 5 to 12 years) have demonstrated significant improvements in body composition, strength, endurance, and flexibility after 12 weeks of combined aerobic activity (games and relays) and resistance training (elastic band exercises ) [12,18].

More recently, a school-based physical activity program called BOKS (Build Our Kids' Success) has been implemented in more than 1,200 schools in the United States and other countries. The BOKS before-school physical activity program is directed by volunteer instructors and provides 50-minute sessions of large muscle exercise 3 days each week. The purpose of this study was to evaluate the effects of the BOKS before- school physical activity program on specific aspects of children's health and fitness: bodyweight, percent body fat, fat weight, lean weight, 
muscle strength, joint flexibility, and aerobic performance.

\section{Methods}

This study was approved by the Institutional Review Board of Quincy College, and by the Weymouth, Massachusetts public school system in which the research was conducted. Two similar elementary schools were chosen by the Weymouth public school system administration for inclusion in the study. Students in Kindergarten through fourth grade are eligible to participate in the BOKS before-school exercise program, and children from all of these grade levels were selected by administrators of the two participating elementary schools for the study assessments. One school did not offer the BOKS before-school physical activity program and served as the control group. The other school provided the BOKS before-school physical activity program for 50 minutes, three days each week, and served as the exercise group. This elementary school had conducted the BOKS beforeschool physical activity program the previous year with the same lead instructor. Students in both elementary schools participated in similar physical education programs directed by full-time physical education teachers employed by the Weymouth public school system.

We decided to conduct the physical assessments at the beginning and end of a 9-week period as this was within the 8 to 12 -week time-frame of our previous youth fitness studies [12,1821] and accommodated the Fall schedule of the Weymouth elementary schools. The before-school exercise program was directed by parent volunteers who completed training courses to become certified BOKS exercise instructors. The BOKS instructor certification program requires active participation in a 6.5-hour workshop and a demonstrated understanding of the BOKS physical activities, educational curriculum, instructional methods, and class management.

The BOKS program was conducted in accordance with dozens of lesson plans that involved a variety of continuous and intermittent physical activities, including group games, running relays, locomotor movements, body weight exercises, and controlled stretches. During each cool-down segment, the students listened to a brief, age-appropriate presentation on a topic related to health, fitness, exercise, nutrition, or sleep. Parents typically car pooled their children to the school playground or gymnasium where they checked-in and did warmup exercises prior to the group activity session.

\section{Participants}

The study subjects included a total of 112 elementary school students in grades K-4. These participants included 81 elementary school students (46 males, 35 females; mean age $7.6 \pm 1.40$ years) who participated in the BOKS before-school exercise program and 31 elementary school students (24 males, 7 females; mean age $8.7 \pm 0.75$ years) who did not participate in the BOKS before-school exercise program. Students in the two participating elementary schools were from similar socioeconomic backgrounds, with an average of $83 \%$ white and $17 \%$ non-white children. All of the study subjects performed their normal daily activities and participated in their scheduled school physical education classes.

There were significant differences between the two study groups. The control group differed significantly $(P<0.05)$ from the exercise group in age, height, body weight $(\mathrm{kg})$, percent fat, lean weight $(\mathrm{kg})$, muscle strength $(\mathrm{kg})$, and aerobic performance (seconds).

Due to the variability of these characteristics, a Mann-Whitney test was administered to determine statistically significant difference between groups. The baseline physical characteristics for the 112 study participants are presented in Table 1.

\section{Procedures}

The role of our research team was strictly to assess selected physical characteristics of the exercise group and control group participants. The assessment equipment stations were located in a separate area away from the gymnasium and playground. The investigators had no involvement in the exercise program, and no interaction with the BOKS instructors during the physical activity sessions. The investigators interacted with the children only when conducting the physical/fitness assessments. The investigators were uniformly friendly and encouraging, and addressed each student by name, as they all wore name tags.

\section{Assessments}

All of the assessments were conducted at the beginning and end of the 9-week study period between October 16, 2014 and December 19, 2014. All of the assessments were performed by the same testing team of experienced and nationally certified exercise science/fitness professionals, with the exception of the 400 meter runs which were administered by the school physical education specialists. Subject assessments included height, body weight, percent body fat, fat weight, lean weight, muscle strength, joint flexibility, and aerobic performance.

Height and body weight were obtained to the nearest onequarter inch $(0.64 \mathrm{~cm})$ and the nearest one-quarter pound $(0.11$ $\mathrm{kg}$ ), respectively, on a manually adjusted balance scale with a

Table 1: Baseline Physical Characteristics of the Study Subjects $(\mathrm{N}=112)$

\begin{tabular}{|c|c|c|}
\hline Characteristic & $\begin{array}{c}\text { Control Group (n } \\
=31 \text { ) }\end{array}$ & $\begin{array}{c}\text { Exercise Group ( } \mathrm{n} \\
=\mathbf{8 1} \text { ) }\end{array}$ \\
\hline Age (years) $* * *$ & $8.65 \pm .75$ & $7.57 \pm 1.40$ \\
\hline Height $(\mathrm{m})^{* *}$ & $1.35 \pm 0.71$ & $1.28 \pm 0.10$ \\
\hline Body Weight (kg)* & $33.21 \pm 5.38$ & $29.50 \pm 7.59$ \\
\hline Percent Fat (\%)* & $15.93 \pm 4.39$ & $18.65 \pm 4.97$ \\
\hline Fat Weight (kg) & $5.47 \pm 2.05$ & $5.72 \pm 2.88$ \\
\hline Lean Weight $(\mathrm{kg}){ }^{* * *}$ & $27.86 \pm 4.05$ & $23.75 \pm 5.15$ \\
\hline Muscle Strength $(\mathrm{kg})^{* *}$ & $12.49 \pm 3.32$ & $10.05 \pm 3.80$ \\
\hline Joint Flexibility $(\mathrm{cm})$ & $34.09 \pm 9.37$ & $33.60 \pm 8.66$ \\
\hline $\begin{array}{l}\text { Aerobic Performance } \\
\text { (seconds)* }\end{array}$ & $124.04 \pm 23.25$ & $134.43 \pm 22.98$ \\
\hline
\end{tabular}

${ }^{\text {a }}$ All values given as mean \pm standard deviation

$*, * *, * * *$ Statistically significant differences between groups at the 0.05 , 0.01 , and $<0.001$ levels, respectively 
height measurement attachment. Body composition assessments, including percent body fat, fat weight, and lean weight, were obtained by means of computerized ultrasound technology (SomaTech). Muscle strength was assessed (best of two trials) by measuring maximum isometric contraction force of the elbow flexor muscles (biceps brachii, radio-brachialis, brachialis) at 90 degrees of elbow flexion with no assisting movement of the hips, back, or shoulders (MicroFit computerized testing system). Joint flexibility was assessed (best of two trials) by measuring maximum forward finger placement on a sit-and-reach apparatus with no flexion of the knees (MicroFit computerized testing system). Aerobic performance was assessed by completion times in the 400 meter run.

\section{Data Analysis}

Normality tests were conducted on all variables used in the data analyses. Due to the variability in the sample of elementary school students (grades K-4), few variables demonstrated normal distribution as evident from Shapiro-Wilk tests $(P>0.05)$. As a result, nonparametric statistical analyses were used to determine if there were significant changes in mean height, body weight, percent body fat, fat weight, lean weight, muscle strength, joint flexibility, and aerobic performance as a result of participation in the BOKS program. The alpha level for statistically significant differences was established at $P=0.05$. All data analyses were performed using IBM SPSS Statistics 20 software.

The Mann-Whitney test was performed on the average change between pre and post-treatment measurements of height, body weight, percent body fat, fat weight, lean weight, muscle strength, joint flexibility, and aerobic performance. Results of the Mann-Whitney test demonstrate whether there was a significant difference in the average change in these characteristics between the exercise and control groups.

Linear regressions were also performed to determine if participation in the BOKS program was a significant predictor of overall average change in measures of height, body weight, percent body fat, fat weight, lean weight, muscle strength, joint flexibility, and aerobic performance. Tests for residual normality were conducted using the Kolmogorov-Smirnov tests. Because of the non-normal distribution of the independent variables, Kolmogorov-Smirnov tests were used rather than Shapiro-Wilk tests. Residuals of the dependent variables - the changes in height, body weight, percent body fat, fat weight, lean weight, muscle strength, joint flexibility, and aerobic performance - were normally distributed $(p>0.05)$.

The linear regression was able to control for all pre-treatment measurements, which was important given that the two groups were significantly different on several measures including height, weight, lean weight, and muscle strength. Age and gender were also added as control measures (Table 2).

\section{Results}

There were no injuries reported by any of the study participants. Three students moved out of the school district, and 13 children were not available for the scheduled retesting
Table 2: Impact of BOKS Program, Controlling for Baseline Characteristics $(\mathrm{N}=100)$.

\begin{tabular}{|c|c|c|c|}
\hline Variable & $\begin{array}{c}\text { Change in } \\
\text { \% Fat }\end{array}$ & $\begin{array}{c}\text { Change in Fat } \\
\text { Weight }\end{array}$ & Change Aerobic \\
\hline Constant & 1.132 & 5.184 & $-142.951^{* * *}$ \\
\hline BOKS Participant & $1.466^{* * *}$ & $0.880^{* *}$ & $8.439^{*}$ \\
\hline Pre-Height & 0.027 & $-0.175^{*}$ & 0.002 \\
\hline Pre-Body Weight & 0.053 & -0.199 & 3.665 \\
\hline Pre-\% Body Fat & 0.047 & -0.024 & $2.932^{* *}$ \\
\hline Pre-Fat Weight & 0.007 & 0.184 & $-7.406^{* *}$ \\
\hline Pre-Lean Weight & 0.059 & 0.236 & -2.65 \\
\hline Pre-Muscle Strength & 0.027 & 0.026 & 0.179 \\
\hline Pre-Joint Flexibility & 0.036 & -0.057 & 0.506 \\
\hline $\begin{array}{c}\text { Pre-Aerobic } \\
\text { Performance }\end{array}$ & 0.001 & 0.001 & $0.405^{* * *}$ \\
\hline Gender (Female) & 0.261 & 0.481 & -5.06 \\
\hline $\begin{array}{c}\text { Age } \\
\text { R-squared }\end{array}$ & 0.199 & .0 .233 & 1.653 \\
\hline Adjusted R-squared & 0.159 & 0.171 & 0.393 \\
\hline $\begin{array}{c}\text { Number } \\
\text { observations }\end{array}$ & 100 & 0.069 & 0.319 \\
\hline$*$ Staticaly & 100 & 100 \\
\hline
\end{tabular}

$*, * *, * * *$ Statistically significant differences between groups at the 0.05 , 0.01 , and $<0.001$ levels, respectively

sessions due to personal illness or family vacation, resulting in a total of 112 students who completed both of the study assessments. Mean changes in height, body weight, percent body fat, fat weight, lean weight, muscle strength, joint flexibility, and aerobic performance for the exercise and control groups are presented in Table 3.

\section{Height}

Mann-Whitney tests revealed no significant differences between the two study groups for changes in height $(P=0.083)$. Subjects in the control group experienced a mean height increase of $0.81 \mathrm{~cm}$ and participants in the exercise group experienced a mean height increase of $1.40 \mathrm{~cm}$. Regression analyses demonstrated that when controlling for baseline measurements, change in height was not significantly associated with participation in the BOKS exercise program.

\section{Body Weight}

Data analysis showed no significant difference between the two study groups for changes in body weight $(P=0.090)$. The control subjects experienced a mean body weight gain of $0.45 \mathrm{~kg}$, and the exercise participants experienced a mean body weight gain of $0.86 \mathrm{~kg}$ over the 9 -week study period. Body weight was also not significantly associated with participation in the BOKS exercise program, even when controlling for other baseline measurements.

\section{Percent Body Fat}

The two study groups experienced significantly different changes in percent body fat. The exercise group experienced a 
Table 3: Changes in Physical Characteristics of the Study Subjects at Week $10(\mathrm{~N}=112)^{\mathrm{a}}$.

\begin{tabular}{|c|c|c|}
\hline Characteristic & $\begin{array}{c}\text { Control Group (n } \\
\mathbf{= ~ 3 1 )}\end{array}$ & $\begin{array}{c}\text { Exercise Group (n } \\
\mathbf{~ = ~ 8 1 ) ~}\end{array}$ \\
\hline Height $(\mathrm{cm})$ & $+0.81 \pm 7.24$ & $+1.40 \pm 9.78$ \\
\hline Body Weight $(\mathrm{kg})$ & $+0.45 \pm 5.48$ & $+0.86 \pm 7.99$ \\
\hline Percent Fat $(\%)$ & $0.00 \pm 4.77$ & $-1.27 \pm 4.99^{*}$ \\
\hline Fat Weight $(\mathrm{kg})$ & $+0.06 \pm 2.14$ & $-0.22 \pm 2.88^{*}$ \\
\hline Lean Weight $(\mathrm{kg})$ & $+0.47 \pm 4.13$ & $+1.06 \pm 5.56$ \\
\hline Muscle Strength $(\mathrm{kg})$ & $+0.12 \pm 2.87$ & $+0.7 \pm 3.52$ \\
\hline Joint Flexibility (cm) & $0.00 \pm 8.53$ & $+1.68 \pm 8.99$ \\
\hline $\begin{array}{c}\text { Aerobic Performance } \\
\text { (seconds) }\end{array}$ & $+2.81 \pm 12.95$ & $-1.13 \pm 23.60^{*}$ \\
\hline
\end{tabular}

${ }^{\text {a }}$ All values given as mean \pm standard deviation

${ }^{*}$ Statistically significant improvement compared to control group $(P<$ 0.05 )

mean $1.27 \%$ reduction in percent body fat, which was significantly greater $(P<0.001)$ than the control group that experienced no change in percent body fat. The average change in percent body fat constituted the largest practical effect of any changes seen in participants of the BOKS exercise program $(r=-0.432)$.

Regression analysis also showed that the change in percent body fat was significantly associated with participation in the BOKS exercise program $(P<0.001)$, even when controlling for baseline characteristics. After controlling for other characteristics, participation in the BOKS exercise program decreased their average percent body fat by $1.47 \%$.

\section{Fat Weight}

Data analysis showed significant differences between the two study groups for changes in fat weight $(P=0.001)$. The control subjects experienced a mean fat weight gain of $0.06 \mathrm{~kg}$, whereas the exercise participants experienced a mean fat weight loss of $0.22 \mathrm{~kg}$. This significant change demonstrated a moderate practical effect $(\mathrm{r}=-0.31)$.

Linear regression demonstrated that when controlling for baseline characteristics, there was a significant association between the average change in fat weight and participation in the BOKS exercise program $(P=0.007)$. After controlling for other characteristics, those who participated in the BOKS exercise program had an average fat weight loss of $0.40 \mathrm{~kg}$.

\section{Lean Weight}

Changes in lean weight were also significant between the two study groups $(P=0.005)$. Subjects in the control group experienced a mean lean weight gain of $0.47 \mathrm{~kg}$, whereas participants in the exercise group experienced a significantly greater mean lean weight gain of $1.06 \mathrm{~kg}$. This significant change demonstrated a moderate practical effect $(r=0.27)$

After running a linear regression and controlling for baseline characteristics, the average change in lean weight was no longer significantly associated with participation in the BOKS exercise program $(P=0.316)$. Instead, baseline measurements of height, fat weight, and aerobic performance, as well as gender, were significant predictors of the change in lean weight. The significant change in lean weight between groups was actually due to the significant differences in characteristics between the two groups.

\section{Muscle Strength}

Data analysis revealed no significant differences between the two study groups for changes in muscle strength $(P=0.170)$. Control group subjects experienced a mean biceps strength increase of $0.12 \mathrm{~kg}$. Exercise group participants experienced a mean biceps strength increase of $0.70 \mathrm{~kg}$, though that was not significantly different from the control group. Regression analyses also demonstrated that when controlling for baseline measurements, change in muscle strength was not significantly associated with participation in the BOKS exercise program.

\section{Joint Flexibility}

There was no significant difference between the two groups in average change in joint flexibility $(P=0.076)$. The exercise group experienced a mean increase in sit-and-reach flexibility of $1.68 \mathrm{~cm}$, which was significantly greater than the control group that experienced no change in sit-and-reach flexibility. However, regression analyses revealed that there was no significant association between joint flexibility and participation in the BOKS exercise program.

\section{Aerobic Performance}

The average change between the two study groups for aerobic performance was significant $(P=0.046)$. The mean 400 meter run time of the control group increased by 2.81 seconds, indicating a slower run performance. The mean 400 run time of the exercise group decreased by 1.13 seconds, indicating a faster run performance. This change may be significant, but has a small practical effect $(\mathrm{r}=-0.20)$.

Linear regression demonstrated that when controlling for baseline characteristics, there was a significant association between the average change in aerobic performance and participation in the BOKS exercise program $(P=0.011)$. After controlling for these characteristics, participation in the BOKS exercise program was associated with an 8.44-second reduction in 400 meter run time.

\section{Discussion}

The control group of elementary-aged children who did not participate in a before-school group exercise program experienced no significant changes in height, body weight, percent body fat, fat weight, lean weight, muscle strength, joint flexibility, or aerobic performance over the 9-week study period. The elementary-aged children who did participate in a before-school group exercise program experienced significant improvements in percent body fat, fat weight, and aerobic performance.

With respect to body weight, the $0.45 \mathrm{~kg}$ weight gain experienced by the control group and the $0.86 \mathrm{~kg}$ weight gain experienced by the exercise group were not statistically different. However, with respect to body composition, the significant difference in percent body fat changes indicated that the 
exercise program had a positive impact on the participants' body composition. The exercise group's adjusted $1.47 \%$ improvement in percent body fat compared favorably to the $1.1 \%$ improvement in percent body fat experienced by non-dieting adult participants in a comprehensive fitness program over a similar 10-week training period [22].

Given the threefold increase in childhood obesity for 6 to 11 year old boys and girls between 1980 and 2010 [1], the significant reduction in percent body fat would appear to be an important finding with practical implications for improving body composition in elementary-aged youth. Body composition is a health-related fitness factor that consists of two mutually exclusive components, fat weight and lean weight. Percent body fat can be improved by reducing fat weight, increasing lean weight, or both. Although the lean weight gain experienced by the BOKS participants was not attributable to the exercise program, the adjusted $0.40 \mathrm{~kg}$ reduction in fat weight was significantly associated with participation in the BOKS physical activity program. The BOKS exercise program participants' significant improvement in body composition was greater than that experienced by youth who completed a standard physical education program [23], or an aerobic activity program [24], as these studies reported no significant changes in body composition. However, preadolescent boys and girls in a previous study who participated in an eight-week after-school strength training program attained a significant increase in lean weight [19].

The exercise group showed more improvement than the control group on the biceps strength assessment ( $0.70 \mathrm{~kg}$ vs. 0.12 $\mathrm{kg}$ ), but the difference was not statistically significant. Although the MicroFit system biceps strength test is a valid and reliable assessment of elbow flexor force production, it may have been too specific to evaluate overall strength improvement resulting from a general physical activity program that did not include specific elbow flexion exercises. It is possible that strength gains may have occurred in the muscles that were primarily involved in the BOKS program body weight exercises (e.g., quadriceps, hamstrings, and gluteals in squats; pectoralis, deltoids, and triceps in push-ups), but strength improvements in these muscles would not be reflected in the biceps strength test. Also, it is possible that training/testing specificity may have played a role in the observed strength changes. All of the physical activities were performed dynamically through relatively large movement ranges, but the MicroFit system biceps test assessed muscle strength isometrically at 90 degrees of elbow flexion.

It was somewhat surprising to find that the greater increase in joint flexibility attained by the exercise participants was not associated with the BOKS program, as many of the physical activities featured a variety of dynamic stretches and full-range exercise movements. It is suggested that a few static stretches performed during the cool-down section of each BOKS class might be helpful for enhancing the children's joint flexibility.

Adult aerobic performance is assessed by graduated exercise on treadmills and cycle ergometers, as well as by field tests such as the 1.5 mile run and the 3 -minute step test $[25,26]$. However, the 400 meter run is a more appropriate assessment of aerobic performance for elementary school boys and girls, as the 1.5 mile run is too long and the 3 -minute step test heart rate monitoring is too challenging for young children. Although largely an anaerobic activity for high school students, the 400 meter run times performed by the study participants (ages 5 to 10 years) were over 2 minutes, indicating a relatively high aerobic component. Unlike the control group participants who did not decrease their run time, the BOKS exercise program participants' 400 meter run time was about 2 seconds faster than their pre-training time. When controlling the baseline characteristics, as well as gender and age, this difference was statistically significant $(P<0.05)$. We also learned that percent body fat, fat weight and initial run performance were significant indicators of a faster run time.

The findings from this study indicate that the BOKS beforeschool exercise program was effective for improving percent body fat, decreasing fat weight, and increasing aerobic performance. No significant differences were found between the exercise group and the control group for changes in height, bodyweight, lean weight, biceps strength, or joint flexibility. While it is plausible that more high-effort strength exercises could generate greater improvements in lean weight and muscle strength, we recommend a cautious approach to program revisions.

Presently, the BOKS curriculum features a commendable blend of purposeful physical activity, cooperative games, and positive interactions that enable elementary school children of varying ages to enjoy exercising together on an every-other day basis throughout the school year. The BOKS program has been uniformly well-received by students, parents, teachers, and administrators, as indicated by the increasing participation of age-eligible children and volunteer instructors, as well as scheduled expansion of the program to other elementary schools in the district (by request of students, parents, and teachers). More specifically, in an unpublished survey, 91\% of 986 BOKS students reported that they would sign up for another BOKS session, $98 \%$ of 573 parents reported that they would re-enroll their child/children in another BOKS session, and 72\% of 226 teachers reported that students in the BOKS program were performing better in class. It is therefore suggested that changes in the activity protocol be made slowly and progressively, while maintaining as much fun and games emphasis as possible.

Within these parameters, we would make a case for more muscle strengthening exercises in the BOKS program, incorporating both bodyweight (internal resistance) and resistance bands (external resistance). Although preadolescent strength training studies have demonstrated excellent results using weight stack machines and free-weights [20,21], these types of resistance equipment are not typically available in elementary school gymnasiums. It is therefore recommended that a variety of resistance band exercises be added to the BOKS physical activity program, as resistance bands are relatively safe, versatile, inexpensive, and easy to store in small spaces. Importantly, resistance band training has been associated with significant strength improvements in elementary-aged children $[12,18]$. Research by Morris and associates [27] has demonstrated that in addition to increasing lean mass $[19,28,29]$, basic and 
brief resistance training can significantly enhance bone mineral density in pre-adolescents. Nine-year old girls who performed standard dumbbell and resistance band exercises increased their bone mineral density four times (6.2\% vs $1.4 \%)$ as much as nineyear old girls who did not do strength training over the 10-month study period [27]. Because the foundation for musculoskeletal development is established during the preadolescent years, the National Strength and Conditioning Association [30] has strongly recommended that children's physical activity programs include age-appropriate resistance exercise.

Muscle strength is also a key factor in facilitating motorskill development in preadolescent youth [31], which appears to be associated with more physically active lifestyles during the childhood and teenage years [32,33]. Because youth who become competent in many motor skills may be more likely to participate in sports and recreational physical activities [34,35], we recommend that the BOKS exercise curriculum incorporates more motor skill training in an integrated and progressive manner. Research indicates that productive motor skill training can be systematically added to physical activity programs in a time-efficient manner [36].

Although this research project assessed changes in selected physical parameters over a relatively brief 9-week training period, other studies have demonstrated that longer duration school-based exercise programs are effective for improving components of physical fitness and increasing physical activity time in elementary aged youth. A 9-month school-based exercise program with 8 to 9 year old children in the United States showed significant improvements in percent body fat and aerobic fitness [37]. Similarly, a 9-month school-based exercise program with 6 to 11 year old youth in Switzerland demonstrated significant improvements in percent body fat and aerobic fitness, with a 3-year follow-up assessment revealing significantly greater aerobic fitness in the exercise group participants compared to the control group participants [38]. A 2011 research review of school-based physical activity programs concluded that highquality intervention programs are effective for increasing physical activity time in children and adolescents [39]. It is therefore suggested that continued participation in the BOKS beforeschool exercise program may facilitate further improvements in the children's body composition and components of physical fitness.

Based on the findings from this study, it would appear that additional research of the BOKS before-school physical activity program is warranted. We recommend that future studies use a longer training period, with assessments taken near the beginning and end of the school year (e.g., September to June). We also suggest including assessments of leg pushing strength (e.g., leg press performance) and upper body pushing strength (e.g., chest press performance) to better evaluate strength changes in the major muscle groups that are more actively involved in the BOKS exercise program.

\section{Conclusion}

The results of this study indicate that the BOKS before-school physical activity program is effective for reducing percent body fat, decreasing fat weight, and increasing aerobic performance in preadolescent boys and girls.

\section{Acknowledgements}

The authors express their sincere appreciation to Dr. Jennifer Curtis-Whipple, Patrick Higgins, Kimberly Richards, Brooke Rosenbauer, Laura Burati, Melinda Fulton, Jessica Lussier, Regina Shea, Samantha Gilbert, Francine Sabat, Michelle Anzalone and Sinceree Clarke-Diego for their most valuable assistance in conducting this research study.

\section{References}

1. Ogden CL, Carrol MD, Kit BK, Flegal KM. Prevalence of childhood and adult obesity in the United States, 2011-2012. JAMA . 2014; 311(8):806-14. doi: 10.1001/jama.2014.732.

2. Cohen D, Voss C, Taylor MJ, Delextrat A, Ogunleye AA, Sandercock GR. Ten-year secular changes in muscular fitness in English children. Acta Paediatr. 2011; 100:e175-7. doi: 10.1111/j.1651-2227.2011.02318.x.

3. Runhaar J, Collard DC, Singh AS, Kemper HC, van Mechelen W, Chinapaw M. Motor fitness in Dutch youth: Differences over a 26year period (1980-2006). J Sci Med Sport. 2010; 13(3):323-8. doi: 10.1016/j.jsams.2009.04.006.

4. Gutin B, Owens S. The influence of physical activity on cardiometabolic biomarkers in youths: A review. Pediatr Exerc Sci. 2011; 23(2):16985.

5. Steen-Johannessen J, Anderssen SA, Kolle E, Andersen LB. Low muscle fitness is associated with metabolic risk in youth. Med Sci Sports Exerc. 2009; 41(7):1361-7. doi: 10.1249/MSS.0b013e31819aaae5.

6. Reichert FF, Baptista Menezes AM, Wells JC, Carvalho Dumith S, Hallal PC. Physical activity as a predictor of adolescent body fatness: a systematic review. Sports Med. 2009; 39(4): 279-94. doi: 10.2165/00007256-200939040-00002.

7. Troiano RP, Berrigan D, Dodd KW, Masse LC, Tilert T, McDowell M. Physical activity in the United States measured by accelerometer. Med Sci Sports Exerc. 2008; 40(1):181-8.

8. Sisson SB, Katzmarzyk PT. International prevalence of physical activity in youth and adults. Obesity Rev. 2008; 9(6):606-14. DOI: 10.1111/j.1467-789X.2008.00506.x.

9. US Department of Health and Services. Physical activity and health: A report of the Surgeon General. Atlanta, GA: Centers for Disease Control and Prevention, National Center for Chronic Disease Prevention and Health Promotion; 1996.

10. Kaiser Family Foundation. Kids \& Media @ the new millennium (monograph). Menlo Park, Cal: Kaiser Family Foundation; 1999.

11. Strasburger VC. Children, adolescents and television. Pediatr Rev. 1992; 13(4):144-51.

12. Annesi JJ, Westcott WL, Faigenbaum AD, Unruh JL. Effects of a 12-week physical activity protocol delivered by YMCA after-school counselors (Youth Fit for Life) on fitness and self-efficacy changes in 5-12-yearold boys and girls. Res Q Exerc Sport. 2005; 76(4):468-76.

13. National Association for Sports and Physical Education. Shape of the nation 1993: A survey of physical education requirements. Reston, VA: American Alliance of Health, Physical Education, Recreation and Dance; 1994.

14. United States Department of Health and Human Services. The 
association between school-based physical activity, including physical education, and academic performance. 2010.

15. National Association of Sports and Physical Education and American Heart Association. Shape of the nation report: Status of physica education in the USA. Reston, Va: American Alliance for Health, Physical Education, Recreation and Dance; 2012

16. McKenzie TL, Feldman H, Woods SE, Romera KA, Dahlstrom V, Stone EJ, et al. Children's activity levels and lesson contexts during thirdgrade physical education. Res Q Exerc Sport. 1995; 66(3):184-93.

17. Simons-Morton B, Taylor WC, Snider SA, Huang IW. The physical activity of fifth-grade students during physical education. Am J Public Health. 1993; 83(2): 262-4.

18. Annesi JJ, Faigenbaum AD, Westcott WL, Smith AE, Dixon GM. Effects of the Youth Fit For Life protocol on physiological factors, mood, self-appraisal, voluntary physical activity, and fruit and vegetable consumption in children enrolled in YMCA after-school care. J Soc Behav Health Sci. 2007; 1(1):86-102. DOI: 10.5590/ JSBHS.2007.01.1.06.

19. Westcott WL, Tolken J, Wessner B. School-based conditioning programs for physically unfit children. J Strength Cond Res. 1995; 17(2):5-9.

20. Faigenbaum AD, Zaichkowsky LD, Westcott WL, Micheli LJ, Fehlandt AF. The effects of a twice-a-week strength training program on children. Pediatr Exerc Sci. 1993; 5(4):339-346.

21. Faigenbaum AD, Westcott WL, Micheli LJ, Outerbridge AR, Long CJ, LaRosa Loud R, et al. The effects of strength training and detraining on children. J Strength Cond Res. 1996; 10(2):109-14.

22. Westcott WL, Apovian CM, Puhala K, Corina L, LaRosa Loud R, Whitehead S, et al. Nutrition programs enhance exercise effects on body composition and resting blood pressure. Phys Sportsmed. 2013; 41(3):85-91. doi: 10.3810/psm.2013.09.2027.

23. Cohen CJ. The effect of a three-year physical fitness program on the body composition and lifestyle behaviors of middle-school students. Res Q Exerc Sport. 1995; 66(1):A29.

24. Ignico AA, Mahon AD. The effects of a physical fitness program on lowfit children. Res Q Exerc Sport. 1995; 66(1): 85-90.

25. American College of Sports Medicine. Guidelines for exercise testing and prescription. $9^{\text {th }}$ ed. Philadelphia: Lippincott, Williams and Wilkins; 2014.

26. Golding LA, Myers CR, Sinning WE. Y's Way to Physical Fitness. $3^{\text {rd }}$ ed. Champaign, IL: Human Kinetics; 1989.

27. Morris FL, Naughton GA, Gibbs JL, Carlson JS, Wark J. Prospective 10-month exercise intervention in premenarcheal girls: Positive effects on bone and lean mass. J Bone Miner Res. 1997; 12(9):1453-62.
28. McGuigan MR, Tatasciore M, Newton RU, Pettigrew S. Eight weeks of resistance training can significantly alter body composition in children who are overweight or obese. J Strength Cond Res. 2009; 23(1):80-5.

29.Velez A, Golem DL, Arent SM. The impact of a 12-week resistance training program on strength, body composition, and self-concept of Hispanic adolescents. J Strength Cond Res. 2010; 24(4):1065-73. doi: 10.1519/JSC.0b013e3181cc230a.

30. National Strength and Conditioning Association. Youth resistance training: Position statement and literature review. Strength Cond J. 1996; 18(6): 62-75.

31. Malina R, Bouchard C, Bar-Or O. Growth, maturation and physical activity. 2nd ed. Champaign, IL: Human Kinetics; 2004.

32. Barnett LM, Van Beurden E, Morgan PJ, Brooks LO, Beard JR. Childhood motor skill proficiency as a predictor of adolescent physical activity. J. Adolesc Health. 2009; 44(3):252-9. doi: 10.1016/j. jadohealth.2008.07.004.

33. Lopes VP, Rodrigues LP, Maia JA, Malina RM. Motor coordination as predictor of physical activity in childhood. Scand J Med Sci Sports. 2011; 21(5):663-9. doi: 10.1111/j.1600-0838.2009.01027.x.

34. Faigenbaum A, Lloyd R, Sheehan D, Myer G. The role of the pediatric exercise specialist in treating exercise deficit disorder in youth. Strength Cond J. 2013; 35(3):34-41.

35. Stodden DF, Goodway JD, Langendorfer SJ, Robertson MA, Rudisill $\mathrm{ME}$, Garcia C, et al. A developmental perspective on the role of motor skill competence in physical activity: An emergent relationship. Quest. 2008; 60(8):290-306. DOI:10.1080/00336297.2008.10483582

36. Faigenbaum AD, Farrell A, Fabiano M, Radler T, Nacierio F, Ratamess NA, et al. Effects of integrative neuromuscular training on fitness performance in children. Pediatr Exerc Sci. 2011; 23(4):573-84. Dol: 10.1542/peds.2013-2246.

37. Kahn NA, Raine LB, Drollette ES, Scudder MR, Pontifex MB, Castelli DM, et al. Impact of the FitKids physical activity intervention on adiposity in prepubertal children. Pediatrics. 2014; 133(4): e875-e83. doi: 10.1542/peds.2013-2246

38. Meyer U, Schindler C, Zahner L, Ernst D, Hebestreit H, van Mechelen $\mathrm{W}$, et al. Long-term effect of a school-based physical activity program (KISS) on fitness and adipositiy in children: A cluster-randomized controlled trial. PLoS One. 2014; 9(2):e87929. Dol: 10.13171/journal. pone.0087929.

39. Kriemler S, Meyer U, Martin E, van Sluijs E, Andersen LB, Martin BW. Effect of school-based interventions on physical activity and fitness in children and adolescents: A review of reviews and systematic update. Br J Sports Med. 2011; 45(11):923-30. Doi: 10.1136/ bjsports-2011-090186. 